\begin{tabular}{|c|c|c|}
\hline 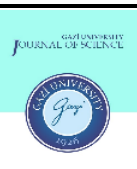 & $\begin{array}{c}\text { Gazi University } \\
\text { Journal of Science }\end{array}$ & 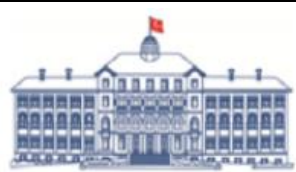 \\
\hline & http://dergipark.gov.tr/gujs & \\
\hline
\end{tabular}

\title{
Goal Programming Model for Production-Distribution Planning by Considering Carbon Emission
}

\author{
Ahmet AKTAS ${ }^{1, *(D)}$, Izzettin TEMIZ ${ }^{2}$ \\ ${ }^{I}$ Gazi University, Department of Industrial Engineering, 06570, Ankara, Turkey \\ ${ }^{2}$ Mersin University, Department of Maritime Business Administration, 33335, Mersin, Turkey
}

\author{
Highlights \\ - Goal programming model for production - distribution planning \\ - Optimization of production and distribution decisions by considering profit and emission. \\ - Integration of lead times into supply planning. \\ - Bill-of-materials information included to the mathematical model. \\ - Test of the proposed model by randomly generated test problems.
}

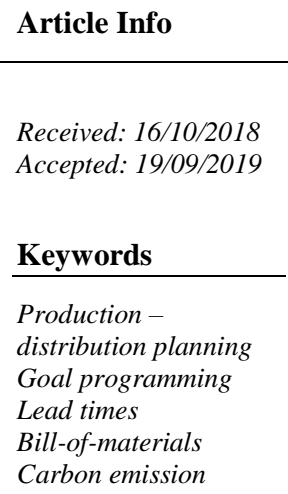

\section{INTRODUCTION}

In today's world, management of production - distribution processes in an aggregated manner is vital for enterprises in order to be successful. While planning production - distribution processes, supply chain management philosophy makes it possible to decrease costs and increase profit. Basically, supply chain management focuses on the control of material flow among the suppliers, production - distribution facilities, and customers to minimize total cost over the supply chain [1].

It is believed that supply chains affect the environment in terms of global warming and carbon emissions [2]. Due to fossil fuels, carbon emissions have increased by 50\% compared to levels of 1990 . The growth in developing economies such as China and India has a high acceleration [3]. Production and transportation of products and materials cause approximately $45 \%$ of these emissions [4]. To protect the world from dangerous climate changes, companies should take into account the potential harm to the environment as they design and operate their supply chains. With the inclusion of environmentalist approaches in supply chain management, efficient consumption of resources, waste management, control of gas emissions, and environmental regulations are gaining importance.

Torabi and Hassini [5] utilized interactive fuzzy goal programming approach to obtain compromise solutions between cost and product quality in production - distribution network. In another study, the 
stochastic multi objective programming model was used to evaluate solutions in terms of profit, product quality and level of customer satisfaction [6]. The strategic and tactical decisions of a multi-product network are obtained by using a mixed integer programming approach and optimizing the net present value [7]. Torabi and Moghaddam [8] tried to find a trade-off point between profit and lead time by using goal programming. Badri et al. [9] developed a solution procedure based on Lagrange Relaxation to determine strategic and tactical level decisions of a supply chain. Paksoy et al. [10] used fuzzy mixed-integer goal programming model in order to obtain the trade-off between raw material quality, purchasing, and remanufacturing costs.

Peidro et al. [11] proposed a fuzzy multi objective linear programming model to optimize profit, idle times and backorder amounts for procurement, production and distribution planning in ceramic tile supply chain. Shaw et al. [12] utilized goal programming approach to find the trade off point between total cost and carbon emissions of materials and logistics activities in supply chains. Ahmadizar and Zeynivand [13] proposed a fuzzy multi objective mathematical programming model to optimize cost, inventory, and back order amounts of a production - distribution network under just in time production environment. In another study, procurement, production, storage and distribution costs of distribution network, and intra-cellular efficiency of cellular manufacturing environment are optimized via goal programming approach [14].

Bill-of-materials information is one of the most important issues related to material management while determining the production-distribution plans. As a result of literature review in this field, it is realized that almost all of the studies in the literature consider bi-level bill-of-materials. Altiparmak et al. [15] developed a genetic algorithm for optimization of cost and customer service level in a supply chain with bi-level bill-of-materials. Bi-level bill-of-materials are seen in the literature commonly, but the usage of three or more level bill-of-materials is more common in real life applications. A few studies in the literature have focused on this situation and in our review only two studies contain bill-of-materials with more than two levels. Pan and Nagi [16] developed a heuristic approach to solve supply chain network design problem in agile manufacturing environment with multi-level bill-of-materials by cost optimization. Su et al. [17] used metaheuristic methods to determine partner selection and production-distribution decisions of manufacturing chains in an aggregated manner.

Belo-Filho et al. [18] used adaptive large neighbourhood search algorithm to solve production and distribution problem of perishable products under consideration of capacity and set up times. Hein and Almeder [19] proposed an integrated supply routing and production planning model. Material supply process was considered as a vehicle routing problem in this model. Product demands are satisfied by production using supplied materials. Moon et al. [20] modelled a production - distribution network, which contains suppliers, manufacturing units, distribution centres, and retail outlets under fuzzy uncertainty. In this bi-objective mixed-integer linear programming problem, total profit maximization and shortage minimization were considered as objective functions. This model also considered the limitation of carbon emission caused by distribution, production, and storage activities in the network as a constraint.

Taxakis and Papadopoulos [21] developed a genetic algorithm for solving production-distribution planning problem in a five stage supply chain. Material and product flows between suppliers, plants, distribution centres, retailers, and customers at minimum cost were considered in this study. Backordering was allowed by additional penalty cost, but inventory holding at distribution centres was not allowed. Khalifehzadeh et al. [22] formulated a mixed integer linear programming model for a three-echelon production distribution system with several transportation systems. Total cost of network and transportation reliability objectives were tried to be optimized by using ranking genetic algorithm and concessive variable neighbourhood search algorithms. Production, distribution, routing and inventory decisions of small furniture companies were integrated as mixed integer linear programming model by Miranda et al. [23]. Existence of one production line and one vehicle was assumed for a short term planning and performance of six relax and fit heuristics were compared. Rafiei et al. [24] proposed a bi-objective mathematical programming model for production-distribution planning problem. In this network, supplied materials from suppliers were produced by manufacturers and finished goods were distributed by distributors to markets. The aim of this model was to minimize cost and to maximize service level by minimizing number of lost sales. 
In literature review, both single-objective and multi-objective models are encountered. Productiondistribution systems are evaluated in terms of economic indicators (cost, profit, net present value), environmental factors, product quality, product facility efficiency, and customer service level. Both exact solution approaches and heuristic methods are used to solve production-distribution models. Goal programming is seen as one of the most common approaches in multi-objective planning problems. The production stage is often considered to be the transformation of materials into products, which means the use of bi-level bill of materials. In the scope of this study, a goal programming model is proposed in order to determine multi-period production-distribution plans in a multi-product supply chain. Contrary to other studies in the literature, a three-level bill of materials is examined in the proposed model and different transport alternatives are considered for material and product transportation. Under transport and production capacity constraints, both profit and carbon emission values are taken into consideration. Another important issue addressed in this model is the integration of delivery times. Due to the existence of different transportation alternatives, delivery times are used in material supply, material transportation, and demand satisfaction processes. In this study, it is aimed to find moderate solutions by considering economic and environmental aspects. To do so, goal programming approach is used.

The rest of the paper is organized as follows: definition of the problem in the study is presented in the second section. Next, a short description of goal programming approach and the proposed model is given in the third section. In the fourth section, the test procedure is explained and test parameters are presented. This paper is finalized in the fifth section with future research proposals.

\section{PROBLEM DEFINITION}

A general production-distribution network consists of six stages: suppliers, material storage, semi-finished production facilities, end product production facility, end product storage, and retailers. The first activity of the network is flow of raw materials from suppliers to material storage. Orders are accepted by suppliers if the order quantity is greater than the minimum order acceptance ratio of supplier capacity. Each supplier can provide specific materials and material transportation can only be done by using specific transportation alternatives. Different distances of suppliers and the use of different transportation alternatives may lead to different lead times at this stage. Material storage capacity is taken into account. Transported raw materials from suppliers are transferred to semi-finished product production plants by considering lead times to the plant. Each semi-finished product can be produced in facilities suitable for the production of the product. Material requirements in these plants are determined by using bill-of-materials information. Structure of bill-of-materials considered in this study is presented in Figure 1 as follows:

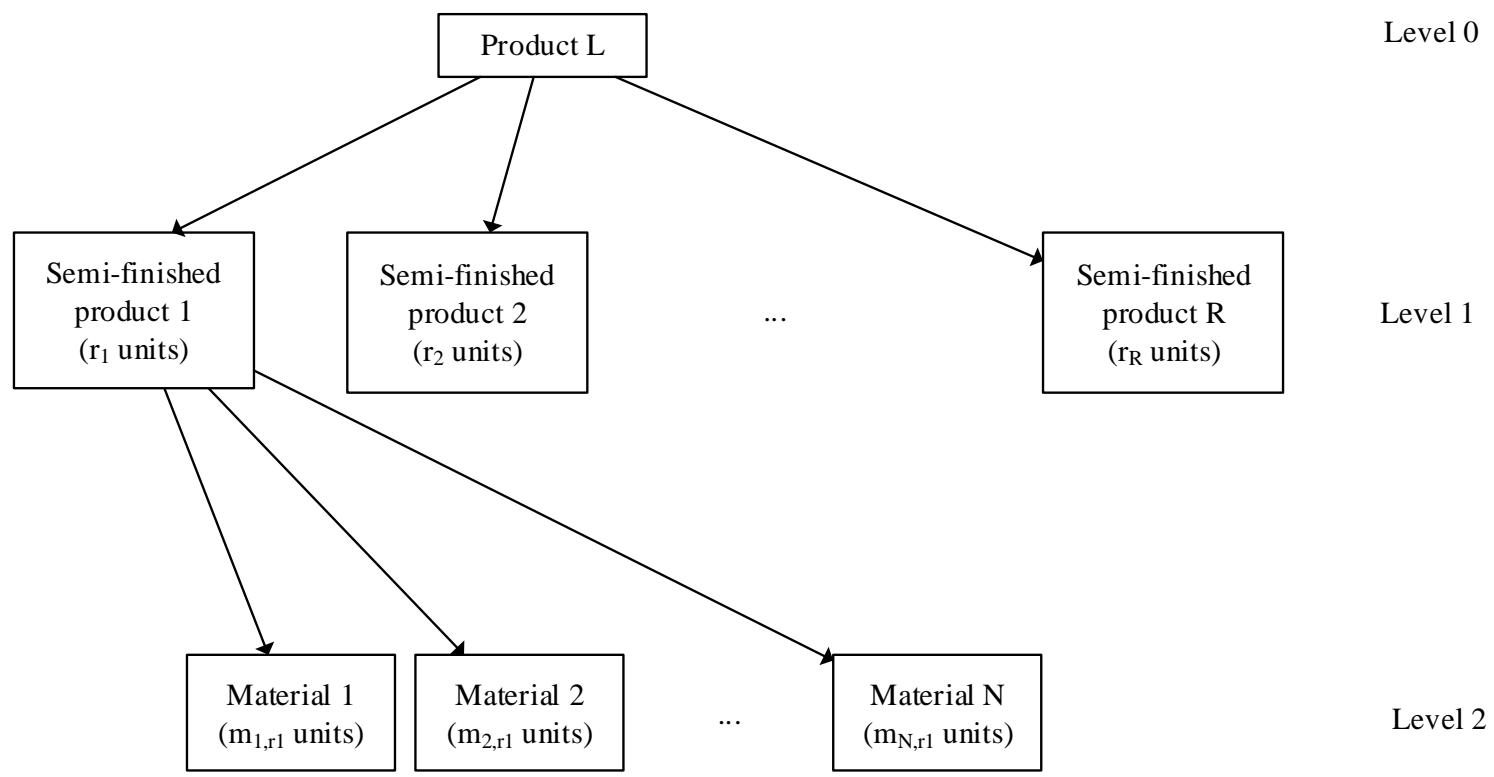

Figure 1. Bill-of-materials structure for product in this study 
Semi-finished products are immediately sent to end product production plant. In this plant, finished products are produced and transferred to the end product storage. End product storage has a certain capacity. Demand of retailers are satisfied by product transportation from this storage. Different product transportation alternatives are available and the distance of the product storage is not equal to all retailers. Therefore, different lead times may occur at this stage. Multi-period production and distribution planning for a multi-product network is aimed. The production distribution network for the model is shown in Figure 2.

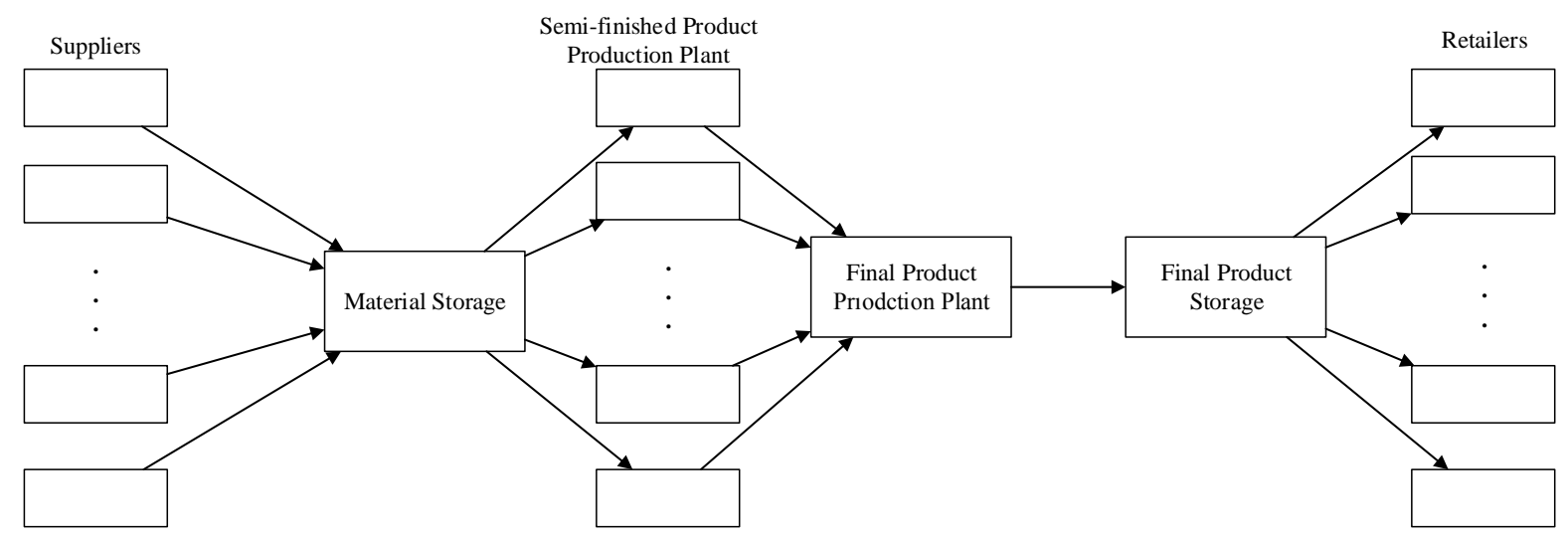

Figure 2. Production - distribution network of the problem

Assumptions of the mathematical model that was developed to optimize the network presented in figure are given as follows:

- Materials can only be supplied from a specific supplier with specific transportation alternatives.

- Suppliers accept orders only if the amount of the order is more than the acceptance rate of their capacity. Otherwise, orders are not accepted.

- Each supplier is located at a different distance to the material storage, so the material lead times are different.

- Material lead times may vary based on the transportation alternative used.

- Material storage has a certain capacity.

- Semi-finished products can only be produced at the production plants which has the technology to produce the product.

- Production capacity of plants and material lead times from material storage is considered at semifinished product production.

- Semi-finished and finished products cannot be stored in production plants.

- Only the materials and finished products can be stored. The materials are stored in the material store and the finished products are stored in the finished product store. Demand of retailers are satisfied by product shipping. Due to the existence of different distances and different transportation alternatives in this stage, lead times may vary.

- Lead times and usage of different transportation alternatives are only considered for stages related to material supply for production and product transportation to retailers.

- Carbon emissions caused by material supply and product transportation are taken into consideration for the optimization in this study.

\section{METHODOLOGY}

In this paper, a goal programming model is proposed to help decision makers in determining multi-period production-distribution planning decisions in a multi-product, multi-stage supply chain. This section presents a short description of goal programming and detailed expression of proposed model. 


\subsection{Goal Programming}

Goal programming is a commonly used solution approach for multi-objective decision-making problems and was firstly proposed in 1955 [25]. There was a limited number of goal programming applications before 1970s, but nowadays this technique is used in a wide application range [26]. Goal programming is used for obtaining solution in different problems such as supplier selection [26], project evaluation [27], and personnel assignment [28]. Basic formulation of goal programming model is given as follows [29]:

$$
\begin{aligned}
& \min \sum_{i=1}^{n}\left|f_{i}(X)-g_{i}\right| \\
& \text { s.t } \\
& X \in F
\end{aligned}
$$

Goal programming model minimizes the total deviation from aspiration levels of each goal. Equation (1) expresses the calculation of total deviation and Equation (2) states that the solution of the problem is in feasible solution area.

Goal programming is a simple approach and it is easy to use. Multi-objective decision problems with a large number of variables and constraints can be handled by goal programming. A detailed description of goal programming can be read in Sen and Nandi's study [30].

\subsection{Proposed Model}

The notations and the decision variables used in the model are explained and the mathematical formulation of the model is given as follows:

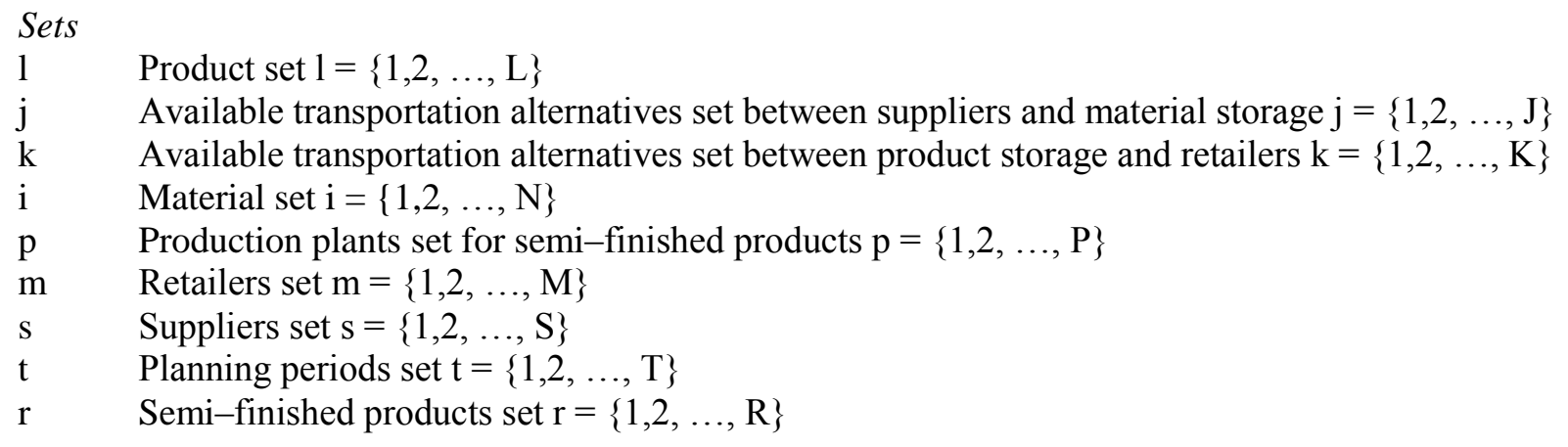

\section{Parameters}

sus $_{\text {isj }} \quad$ availability of material type $i$ at supplier $s$ that can be shipped by transportation alternative $j$

$\mathrm{lb}_{\mathrm{is}} \quad$ Minimum capacity ratio of supplier $s$ to accept an order for material $i$

sup $_{\mathrm{rp}} \quad$ Availability of semi-finished product $r$ to be produced in production plant $p$

caps $_{\text {is }} \quad$ Maximum amount of material $i$ that can be supplied from supplier $s$

capj $j_{j} \quad$ Transportation vehicle capacity for transportation alternative $j$

$\mathrm{capk}_{\mathrm{k}}$ Transportation vehicle capacity for transportation alternative $k$

$\mathrm{vi}_{\mathrm{i}} \quad$ Volume of material $i$

capi Storage capacity of material storage

capp $_{\mathrm{p}} \quad$ Production capacity of semi-finished product production plant $p$

$\mathrm{ar}_{\mathrm{r}} \quad$ Unit production time of semi-finished product $r$

$\mathrm{br}_{\mathrm{ri}} \quad$ Unit amount of material $i$ to produce semi-finished product $r$

$\mathrm{al}_{l} \quad$ Unit production time of product $l$

capl Production capacity of end product production plant

$\mathrm{bl}_{\mathrm{lr}} \quad$ Unit amount of semi-finished product $r$ to produce product $l$

$\mathrm{vl}_{l} \quad$ Volume of product $l$ 
cap Storage capacity for finished products

$\mathrm{D}_{\mathrm{lmt}} \quad$ Demand of retailer $m$ in period $t$ for product $l$

${ } \mathrm{lts}_{\mathrm{sj}} \quad$ Lead time for transportation alternative $j$ from supplier $s$ to material storage

$\operatorname{ltp}_{\mathrm{p}} \quad$ Lead time from material storage to semi-finished product production plant $p$

$\mathrm{ltm}_{\mathrm{km}} \quad$ Lead time for transportation alternative $k$ from product storage to retailer $m$

capa Vehicle capacity for transportation to semi-finished product production plant

M A sufficiently big number

vel $_{j} \quad$ Distance that can be covered by using material transportation alternative $j$

velk $_{\mathrm{k}}$ Distance that can be covered by using product transportation alternative $k$

$\operatorname{cost}_{j} \quad$ Unit transportation cost per kilometer for material transportation alternative $j$

$\operatorname{costk}_{\mathrm{k}}$ Unit transportation cost per kilometer for product transportation alternative $k$

$\mathrm{ej}_{\mathrm{j}} \quad$ Unit carbon emission per kilometer for material transportation alternative $j$

$\mathrm{ek}_{\mathrm{k}} \quad$ Unit carbon emission per kilometer for product transportation alternative $k$

diss $_{\mathrm{s}} \quad$ Distance between material storage and supplier $s$

$\operatorname{disp}_{\mathrm{p}} \quad$ Distance between material storage and semi-finished product production plant $p$

$\operatorname{dism}_{\mathrm{m}}$ Distance between finished product storage and retailer $m$

\section{Coefficients}

$\mathrm{SP}_{1} \quad$ Selling price of product $l$

$\mathrm{A}_{\text {is }} \quad$ Ordering cost of material $i$ from supplier $s$

$\mathrm{cs}_{\mathrm{is}} \quad$ Unit purchasing cost of material $i$ from supplier $s$

$\mathrm{cj}_{\mathrm{sj}} \quad$ Transportation cost per vehicle from supplier $s$ by using transportation alternative $j$

$\mathrm{cp}_{\mathrm{p}} \quad$ Transportation cost per vehicle from material storage to plant $p$

$\mathrm{cr}_{\mathrm{rp}} \quad$ Unit labor cost for producing semi-finished product $r$ in plant $p$

$\mathrm{cl}_{1} \quad$ Unit labor cost for producing product $l$

$\mathrm{cm}_{\mathrm{km}} \quad$ Transportation cost per vehicle to retailer $m$ by using transportation alternative $k$

$\mathrm{hi}_{\mathrm{i}} \quad$ Unit storage cost for material $i$

$\mathrm{hl}_{1} \quad$ Unit storage cost for product $l$

$\mathrm{es}_{\mathrm{sj}} \quad$ Carbon emission amount per vehicle for material transportation from supplier $s$ by using transportation alternative $j$

$\mathrm{em}_{\mathrm{km}}$ Carbon emission amount per vehicle for product transportation to retailer $m$ by using transportation alternative $k$

$\lambda \quad$ Unit penalty cost for carbon emission that exceeds the allowed amount

\section{Decision Variables}

$\mathrm{Xi}_{\mathrm{isjt}} \quad$ Material amount of $\mathrm{i}$ transported from supplier $\mathrm{s}$ to the material storage by using transportation alternative $\mathrm{j}$ in period $\mathrm{t}$

$\mathrm{Xs}_{\mathrm{ist}} \quad$ Material amount of $\mathrm{i}$ purchased from supplier $\mathrm{s}$ in period $\mathrm{t}$

$\mathrm{Xj}_{\mathrm{sjt}} \quad$ Number of vehicles used in period $\mathrm{t}$ for transportation from supplier $\mathrm{s}$ by using transportation alternative $\mathrm{j}$

$\mathrm{X}_{\mathrm{ipt}} \quad$ Material amount of $i$ transported from the material storage to plant $p$ in period $t$

$\mathrm{Xp}_{\mathrm{pt}} \quad$ Number of vehicles used for material transportation to plant $p$ in period $t$

$\mathrm{Xr}_{\mathrm{rpt}} \quad$ The amount of semi-finished product $r$ produced at plant $p$ in period $t$

$\mathrm{Xl}_{\text {lt }} \quad$ The amount of product $l$ produced in period $t$

$\mathrm{Xm}_{\mathrm{lkmt}}$ The amount of product $l$ transported by using transportation alternative $k$ to retailer $m$ in period $t$

$\mathrm{Xk}_{\mathrm{kmt}}$ Number of vehicles used to transport products to retailer $m$ by transportation alternative $k$ in period

$t$

$\mathrm{I}_{\mathrm{it}} \quad$ Storage amount of material $i$ in period $t$

$\mathrm{Il}_{\mathrm{lt}} \quad$ Storage amount of product $l$ in period $t$

$\mathrm{Y}_{\text {ist }} \quad$ Binary variable for the supply of material $i$ from supplier $s$ in period $t$

$\mathrm{Z} \quad$ Weighted deviation value

$Z_{1} \quad$ Aspiration level for the profit

$\mathrm{Z}_{2} \quad$ Aspiration level for the emission value

$\mathrm{d}_{\mathrm{w}}{ }^{+} \quad$ Positive deviation value for $\mathrm{w}^{\text {th }}$ goal

$\mathrm{d}_{\mathrm{w}}{ }^{-} \quad$ Negative deviation value for $\mathrm{w}^{\text {th }}$ goal 


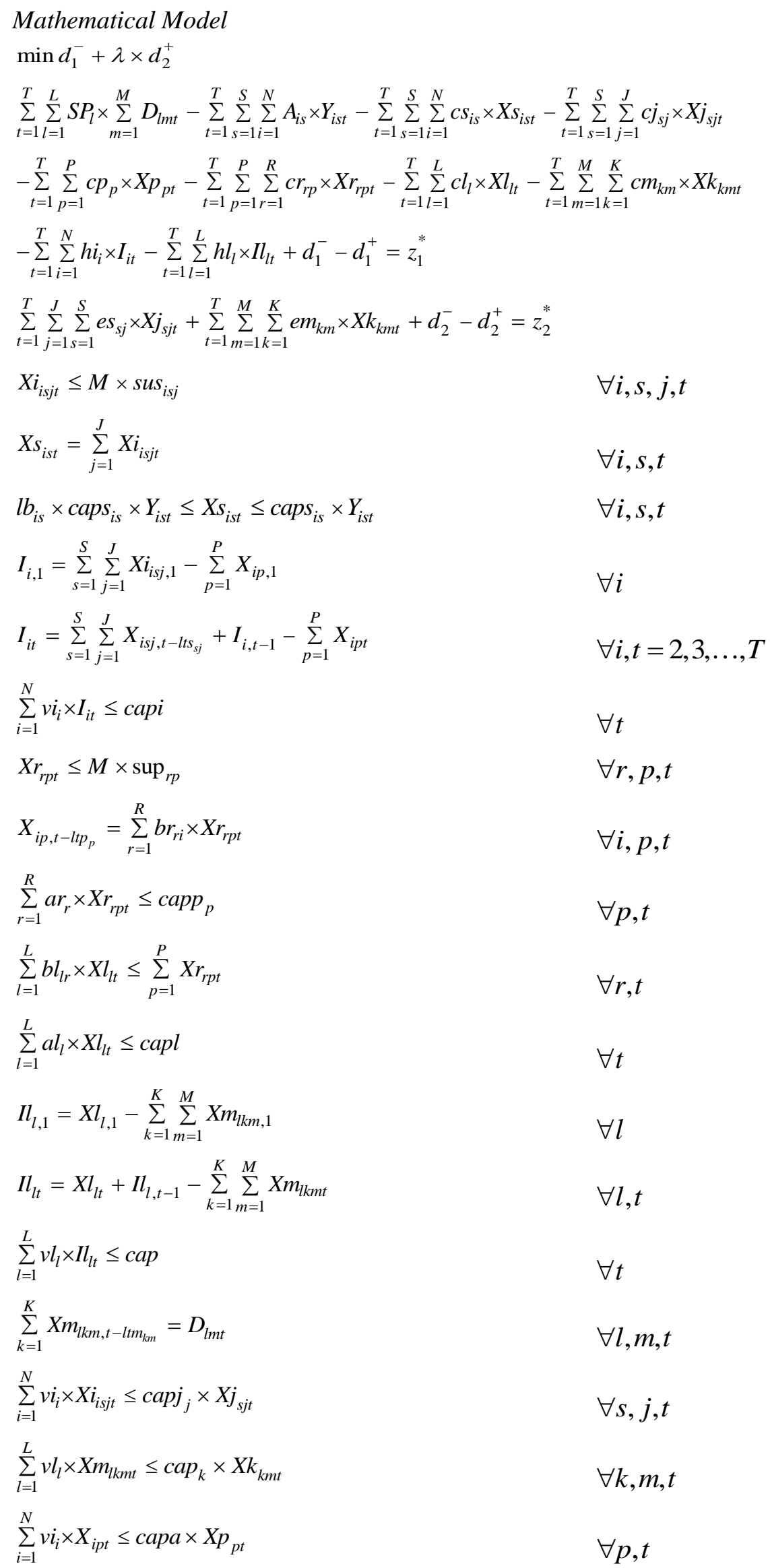




$$
\begin{array}{ll}
X i_{i s j t}, X s_{i s t}, X j_{s j t}, X_{i p t}, X p_{p t}, X r_{r p t}, X l_{l t}, & \\
X m_{l k m t}, X k_{k m t}, I_{i t}, I l_{l t} \geq 0 \text { and integer } & \forall i, j, k, l, m, p, r, s, t \\
Y_{i s t} \in\{0,1\} & \forall i, s, t
\end{array}
$$

Equation (3) is the objective function of the model. The aim of the model is the minimization of the sum of the negative deviation from the profit and penalty cost of positive deviation from the emission. Goal constraints of the model are given in Equation (4) and Equation (5). The former shows the profit value for network activities and is defined as the difference between the revenue obtained by selling products and total cost. The latter shows the carbon emission value. Equation (6) indicates that materials can only be supplied from available suppliers and by using available transportation alternatives. Equation (7) ensures that total amount of purchased materials from a supplier is equal to the total transported amount to material storage by using all available transportation alternatives. Equation (8) states that available supply amount for materials takes values between the minimum acceptable amount for supplier and the supply capacity of supplier. Equations (9) and (10) are the balance equations for materials. Capacity constraint of material storage is denoted in Equation (11). The semi-finished products can only be produced in some plants, which is denoted in Equation (12). Equation (13) states that the amount of material entering into the plant $p$ should be equal to the amount that is used in production at that plant. Semi-finished product production capacity is expressed by Equation (14).

Equation (15) satisfies that the amount of semi-finished products leaving the semi-finished product production plants is equal to the amount used in the production of end products. End product production capacity constraint is expressed in Equation (16). Equations (17) and (18) are the balance equations of end products. Equation (19) satisfies the end product storage capacity.

Equation (20) ensures that the demands of retailers are satisfied by the transportation of products. Equations (21) - (23) are used to express the transportation amounts in terms of the number of transportation vehicles. Equations (24) - (25) are the sign restrictions of the decision variables.

\section{NUMERICAL EXPERIMENTS}

The proposed goal programming model which considers material requirements constraints for multiperiod, multi-stage, multi-product supply chains with different transportation alternatives was tested by generating test problems at various dimensions. The effect of changes in the number of products, semifinished products and materials was investigated in this test procedure. Therefore, 27 different test problems with combinations of 2, 3 and 4 products, 2, 3 and 4 semi- finished products and 3,5 and 8 materials were created randomly. Model size of test problems in views of number of decision variables and constraints are presented in Table 1. 
Table 1. Model size of test problems

\begin{tabular}{|c|c|c|c|c|c|}
\hline Test Problem & $\begin{array}{c}\text { \# of } \\
\text { Products }\end{array}$ & $\begin{array}{c}\text { \# of Semi-Finished } \\
\text { Products }\end{array}$ & $\begin{array}{c}\text { \# of } \\
\text { Materials }\end{array}$ & $\begin{array}{c}\text { \# of Decision } \\
\text { Variables }\end{array}$ & \# of Constraints \\
\hline P1 & 2 & 2 & 3 & 1897 & 2086 \\
\hline $\mathrm{P} 2$ & 2 & 2 & 5 & 2617 & 2952 \\
\hline P3 & 2 & 2 & 7 & 3338 & 3819 \\
\hline P4 & 2 & 3 & 3 & 1945 & 2158 \\
\hline P5 & 2 & 3 & 5 & 2665 & 3026 \\
\hline P6 & 2 & 3 & 7 & 3386 & 3891 \\
\hline P7 & 2 & 4 & 3 & 1994 & 2233 \\
\hline P8 & 2 & 4 & 5 & 2712 & 3097 \\
\hline P9 & 2 & 4 & 7 & 3434 & 3963 \\
\hline P10 & 3 & 2 & 3 & 2089 & 2177 \\
\hline P11 & 3 & 2 & 5 & 2810 & 3035 \\
\hline P12 & 3 & 2 & 7 & 3530 & 3912 \\
\hline P13 & 3 & 3 & 3 & 2137 & 2248 \\
\hline P14 & 3 & 3 & 5 & 2857 & 3117 \\
\hline P15 & 3 & 3 & 7 & 3578 & 3987 \\
\hline P16 & 3 & 4 & 3 & 2186 & 2324 \\
\hline P17 & 3 & 4 & 5 & 2906 & 3193 \\
\hline P18 & 3 & 4 & 7 & 3626 & 4056 \\
\hline P19 & 4 & 2 & 3 & 2282 & 2265 \\
\hline $\mathrm{P} 20$ & 4 & 2 & 5 & 3002 & 3139 \\
\hline $\mathrm{P} 21$ & 4 & 2 & 7 & 3722 & 4009 \\
\hline $\mathrm{P} 22$ & 4 & 3 & 3 & 2330 & 2345 \\
\hline $\mathrm{P} 23$ & 4 & 3 & 5 & 3050 & 3211 \\
\hline P24 & 4 & 3 & 7 & 3770 & 4081 \\
\hline $\mathrm{P} 25$ & 4 & 4 & 3 & 2378 & 2413 \\
\hline P26 & 4 & 4 & 5 & 3098 & 3283 \\
\hline P27 & 4 & 4 & 7 & 3818 & 4149 \\
\hline
\end{tabular}

To solve the model, two different single-objective mixed integer programming models were created by expressing goal constraints as objective functions. The aspiration levels for goal programming model were obtained by solving these two single-objective models and then the goal programming model was solved. Parameters, which are varying according to the product, semi - finished product and material numbers were generated from the discrete uniform distribution as it is in [5], [8] and [9]. Parameters that are independent of product, semi-finished product and material numbers were determined as constant values. Assumptions and value ranges for model parameters are given in Table 2 and Table 3, respectively. 
Table 2. Constant parameter values

\begin{tabular}{|l|l|l|l|}
\hline Parameter & Value & Parameter & Value \\
\hline $\mathrm{J}$ & 2 & capl & 11500 \\
\hline $\mathrm{K}$ & 2 & cap & 10000 \\
\hline $\mathrm{P}$ & 2 & capk $_{\mathrm{k}}$ & 50000 if $k=1,40000$ if $k=2$ \\
\hline $\mathrm{M}$ & 3 & $\operatorname{velj}_{\mathrm{j}}$ & 400 if $j=1,700$ if $j=2$ \\
\hline $\mathrm{S}$ & 3 & $\operatorname{velk}_{\mathrm{k}}$ & 400 if $k=1,700$ if $k=2$ \\
\hline $\mathrm{T}$ & 24 & cost $_{\mathrm{j}}$ & 1.5 if $j=1,2$ if $j=2$ \\
\hline caps is $_{\mathrm{i}}$ & 10000 (for each material and for each supplier) & costk $_{\mathrm{k}}$ & 1.5 if $k=1,2$ if $k=2$ \\
\hline capj $\mathrm{j}_{\mathrm{j}}$ & 75000 (for each $j$ transportation alternative) & $\mathrm{ej}_{\mathrm{j}}$ & 2.5 if $j=1,3.5$ if $j=2$ \\
\hline capi & 20000 & $\mathrm{ek}_{\mathrm{k}}$ & 2.5 if $k=1,3.5$ if $k=2$ \\
\hline capp & 23000 (for each production plant $p$ ) & $\lambda$ & 15 \\
\hline
\end{tabular}

Table 3. Randomly generated parameter values

\begin{tabular}{|l|l|l|l|}
\hline Parameter & Value / Value Range & Parameter & Value / Value Range \\
\hline sus $_{\text {is }}$ & 0 or 1 & dism $_{\mathrm{m}}$ & $U(100,1000)$ \\
\hline $\mathrm{lb}_{\mathrm{is}}$ & $U(0.10,0.15)$ & $\mathrm{D}_{\mathrm{lmt}}$ & $U(50,100)$ \\
\hline $\mathrm{sup}_{\mathrm{rp}}$ & 0 or 1 & $\mathrm{em}_{\mathrm{km}}$ & dism $_{m} \times e k_{k}$ \\
\hline $\mathrm{vi}_{\mathrm{i}}$ & $U(10,19)$ & $\mathrm{SP}_{\mathrm{l}}$ & $U(350,500)$ \\
\hline $\mathrm{ar}_{\mathrm{r}}$ & $U(10,15)$ & $\mathrm{c}_{\mathrm{p}}$ & $U(0.1,0.2) \times$ disp $_{p}$ \\
\hline $\mathrm{br}_{\mathrm{ri}}$ & $U(0,4)$ & $\mathrm{c}_{\mathrm{rp}}$ & $U(1,3)$ \\
\hline $\mathrm{al}_{1}$ & $U(5,10)$ & $\mathrm{c}_{1}$ & $U(4,8)$ \\
\hline $\mathrm{bl}_{\mathrm{lr}}$ & $U(0,3)$ & $\mathrm{c}_{\mathrm{km}}$ & $U(1.25,2) \times$ dism $_{m} \times \operatorname{costk}_{k}$ \\
\hline $\mathrm{vl}_{\mathrm{l}}$ & $U(40,49)$ & $\mathrm{hi}_{\mathrm{i}}$ & $U(0.1,0.2) \times v i_{i}$ \\
\hline $\operatorname{diss}_{\mathrm{s}}$ & $U(500,2000)$ & $\mathrm{hl}_{1}$ & $U(0.1,0.3) \times v l_{l}$ \\
\hline $\operatorname{disp}_{\mathrm{p}}$ & $U(100,400)$ & $\mathrm{es}_{\mathrm{sj}}$ & diss $_{s} \times e j_{j}$ \\
\hline $\operatorname{lts}_{\mathrm{sj}}$ & $\left\lceil\right.$ diss $_{s} /$ velj $\left._{j}\right\rceil$ & $\mathrm{ltm}_{\mathrm{km}}$ & $\left\lceil\right.$ disr $_{r} /$ velk $\left._{k}\right\rceil$ \\
\hline $\mathrm{ltp}_{\mathrm{p}}$ & $\left\lceil\right.$ disp $\left._{p} / 300\right\rceil$ & & \\
\hline
\end{tabular}

The proposed model was coded in GAMS optimization package software. Firstly, generated test problems were solved as single-objective problems to define aspiration levels for goal constraints. Then, results of single - objective problems were written as right hand side values of goal constraints. The objective of goal programming model was the minimization of the sum of negative deviation of profit and the penalty cost of positive deviation of the carbon emission. Penalty cost for per positive deviation from aspiration level of carbon emission was assumed to be 15 . A moderate solution for both objectives was obtained by solving goal programming model.

The proposed model was solved via CPLEX solver of GAMS 22.5 optimization package software on personal computers with Intel ${ }^{\circledR}$ Core ${ }^{\mathrm{TM}}$ i5-4590 $3.30 \mathrm{GHz}$ processor and 8 GB RAM. The obtained results are given in Table 4, Table 5 and Table 6. 
Table 4. Solution results for profit objective

\begin{tabular}{|c|c|c|c|c|c|}
\hline Test Problem & Products & $\begin{array}{c}\text { Semi-Finished } \\
\text { Products }\end{array}$ & Materials & Solution Value & $\begin{array}{c}\text { Solution Time } \\
(\mathrm{sec})\end{array}$ \\
\hline P1 & 2 & 2 & 3 & 782987.80 & 95 \\
\hline P2 & 2 & 2 & 5 & 470724.80 & 969 \\
\hline P3 & 2 & 2 & 7 & 937037.60 & $*$ \\
\hline P4 & 2 & 3 & 3 & 825912.50 & 179 \\
\hline P5 & 2 & 3 & 5 & 515665.80 & 802 \\
\hline P6 & 2 & 3 & 7 & 526277.30 & $*$ \\
\hline P7 & 2 & 4 & 3 & 507048.60 & $*$ \\
\hline P8 & 2 & 4 & 5 & 188075.90 & $*$ \\
\hline P9 & 2 & 4 & 7 & 294476.00 & $*$ \\
\hline P10 & 3 & 2 & 3 & 1738409.70 & 204 \\
\hline P11 & 3 & 2 & 5 & 1297874.80 & 1338 \\
\hline P12 & 3 & 2 & 7 & 818176.90 & $*$ \\
\hline P13 & 3 & 3 & 3 & 1256590.80 & 12 \\
\hline P14 & 3 & 3 & 5 & 709290.00 & 1019 \\
\hline P15 & 3 & 3 & 7 & 494656.40 & $*$ \\
\hline P16 & 3 & 4 & 3 & 299108.60 & $*$ \\
\hline P17 & 3 & 4 & 5 & 613803.30 & $*$ \\
\hline P18 & 3 & 4 & 7 & 298149.00 & $*$ \\
\hline P19 & 4 & 2 & 3 & 2171261.60 & $*$ \\
\hline P20 & 4 & 2 & 5 & 1740681.90 & $*$ \\
\hline P21 & 4 & 2 & 7 & 662166.40 & $*$ \\
\hline P22 & 4 & 3 & 3 & 2019258.90 & $*$ \\
\hline P23 & 4 & 3 & 5 & 1311170.10 & $*$ \\
\hline P24 & 4 & 3 & 7 & 447343.20 & $*$ \\
\hline P25 & 4 & 4 & 3 & 1562549.40 & $*$ \\
\hline P26 & 4 & 4 & 7 & 369611.90 & $*$ \\
\hline P27 & 4 & 4 & & & $*$ \\
\hline$*$ sign indicates the best possible integer solution & of the problem obtained in 7200 seconds \\
\hline & & & & \\
\hline
\end{tabular}

Table 4 shows the solution values and the solution times based on profit maximization for the generated test problems with varying numbers of products, semi-finished products and materials. The solution values with the sign of * indicate the best possible integer solution of the problems after the run of 7200 seconds.

According to the obtained results, it is clear to say that the profit of the network increases as the number of products increases and decreases as the number of materials increases. Also, an increase in the number of semi-finished products generally decreases the profit value. This situation can be explained by obtaining more revenue when the network consists of more products. On the contrary, when the network consists of more materials and semi-finished products, it causes more cost of purchasing, inventory holding, and transportation.

If the results are examined in view of solution times, it can be said that an increase in product, semi-finished product and material numbers yields longer solution times. It can be said for this situation that as the number of elements increases in a network, it becomes more complex to solve the model of that network. 
Table 5. Solution values for the emission objective

\begin{tabular}{|c|c|c|c|c|c|}
\hline Test Problem & Products & Semi-Finished Products & Materials & Solution Value & Solution Time (sec) \\
\hline P1 & 2 & 2 & 3 & 199402.00 & 115 \\
\hline P2 & 2 & 2 & 5 & 653945.00 & $*$ \\
\hline P3 & 2 & 2 & 7 & 409087.00 & $*$ \\
\hline P4 & 2 & 3 & 3 & 464187.50 & $*$ \\
\hline P5 & 2 & 3 & 5 & 4333425.00 & $*$ \\
\hline P6 & 2 & 3 & 7 & 644742.00 & $*$ \\
\hline P7 & 2 & 4 & 3 & 229891.00 & $*$ \\
\hline P8 & 2 & 4 & 5 & 885412.50 & $*$ \\
\hline P9 & 2 & 4 & 7 & 943390.00 & $*$ \\
\hline P10 & 3 & 2 & 3 & 213969.00 & $*$ \\
\hline P11 & 3 & 2 & 5 & 367997.50 & $*$ \\
\hline P12 & 3 & 2 & 7 & 1100857.00 & $*$ \\
\hline P13 & 3 & 3 & 3 & 307323.00 & $*$ \\
\hline P14 & 3 & 3 & 5 & 500500.00 & $*$ \\
\hline P15 & 3 & 3 & 7 & 797803.00 & $*$ \\
\hline P16 & 3 & 4 & 3 & 708918.00 & $*$ \\
\hline P17 & 3 & 4 & 5 & 1052935.00 & $*$ \\
\hline P18 & 3 & 4 & 7 & 1211814.00 & $*$ \\
\hline P19 & 4 & 2 & 3 & 296537.00 & $*$ \\
\hline P20 & 4 & 2 & 5 & 785271.00 & $*$ \\
\hline P21 & 4 & 2 & 7 & 1163170.00 & $*$ \\
\hline P22 & 4 & 3 & 3 & 265928.00 & $*$ \\
\hline P23 & 4 & 3 & 7 & 2500861.00 & $*$ \\
\hline P24 & 4 & 3 & 5 & 1264122.50 & $*$ \\
\hline P25 & 4 & 4 & 2692650.00 & $*$ \\
\hline P26 & 4 & 4 & & & $*$ \\
\hline P27 & 4 & 4 & 2 & & $*$ \\
\hline$*$ sign indicates the best possible integer solution & & & $*$ \\
\hline
\end{tabular}

Table 5 shows the solution values and solution times for the same problems based on carbon emission minimization. Similar to profit objective run results, the solution values with the sign of $*$ indicates the best possible integer solution of the problems after the run of 7200 seconds.

The obtained results show that a rise in the product and material numbers increases the carbon emission value over the network. Also, a rise in the semi-finished product number generally increases the emission value because of the requirement of more materials.

The reason that the model does not reach the optimal solution is the complex structure of the problem. It is not possible to narrow down the solution space by cutting operations within the defined solution time and the solution is just affected by only two decision variables. 
Table 6. Solution results of the goal programming model

\begin{tabular}{|c|c|c|c|c|c|c|}
\hline $\begin{array}{c}\text { Test } \\
\text { Problem }\end{array}$ & Products & Semi-Finished Products & Materials & $\begin{array}{l}\text { Solution } \\
\text { Value }\end{array}$ & $\mathrm{d}_{1}^{+}(\%)$ & $\mathrm{d}_{2}^{-}(\%)$ \\
\hline $\mathrm{P} 1 *$ & 2 & 2 & 3 & 131575.50 & $10.56 \%$ & $1.63 \%$ \\
\hline $\mathrm{P} 2 *$ & 2 & 2 & 5 & 327714.00 & $39.03 \%$ & $1.47 \%$ \\
\hline $\mathrm{P} 3$ & 2 & 2 & 7 & \multicolumn{3}{|c|}{ no integer solution found } \\
\hline $\mathrm{P} 4 *$ & 2 & 3 & 3 & 149660.10 & $16.97 \%$ & $0.14 \%$ \\
\hline $\mathrm{P} 5 *$ & 2 & 3 & 5 & 144754.80 & $28.07 \%$ & $0.00 \%$ \\
\hline P6 * & 2 & 3 & 7 & 138627.50 & $26.34 \%$ & $0.00 \%$ \\
\hline $\mathrm{P} 7 *$ & 2 & 4 & 3 & 221149.40 & $20.01 \%$ & $3.47 \%$ \\
\hline P8 * & 2 & 4 & 5 & 270393.70 & $138.25 \%$ & $0.08 \%$ \\
\hline $\mathrm{P} 9 *$ & 2 & 4 & 7 & 941056.20 & $78.29 \%$ & $5.02 \%$ \\
\hline $\mathrm{P} 10$ & 3 & 2 & 3 & 352053.30 & $20.25 \%$ & $0.00 \%$ \\
\hline $\mathrm{P} 11 *$ & 3 & 2 & 5 & 414852.70 & $29.12 \%$ & $0.67 \%$ \\
\hline $\mathrm{P} 12 *$ & 3 & 2 & 7 & 1088984.80 & $70.44 \%$ & $3.10 \%$ \\
\hline $\mathrm{P} 13 *$ & 3 & 3 & 3 & 617826.80 & $19.06 \%$ & $8.21 \%$ \\
\hline $\mathrm{P} 14 *$ & 3 & 3 & 5 & 336114.00 & $12.26 \%$ & $3.32 \%$ \\
\hline $\mathrm{P} 15$ & 3 & 3 & 7 & \multicolumn{3}{|c|}{ no integer solution found } \\
\hline $\mathrm{P} 16 *$ & 3 & 4 & 3 & 394033.70 & $57.71 \%$ & $2.08 \%$ \\
\hline $\mathrm{P} 17 *$ & 3 & 4 & 5 & 3192147.30 & $33.17 \%$ & $18.92 \%$ \\
\hline $\mathrm{P} 18 *$ & 3 & 4 & 7 & 13667428.10 & $162.79 \%$ & $72.52 \%$ \\
\hline $\mathrm{P} 19 *$ & 4 & 2 & 3 & 86976.00 & $2.64 \%$ & $0.67 \%$ \\
\hline $\mathrm{P} 20 *$ & 4 & 2 & 5 & 982974.10 & $6.08 \%$ & $7.45 \%$ \\
\hline $\mathrm{P} 21 *$ & 4 & 2 & 7 & 1567306.90 & $235.27 \%$ & $0.05 \%$ \\
\hline P22 & 4 & 3 & 3 & 132069.10 & $6.54 \%$ & $0.00 \%$ \\
\hline $\mathrm{P} 23 *$ & 4 & 3 & 5 & 2946991.30 & $17.57 \%$ & $15.11 \%$ \\
\hline P24 & 4 & 3 & 7 & \multicolumn{3}{|c|}{ no integer solution found } \\
\hline $\mathrm{P} 25$ & 4 & 4 & 3 & \multicolumn{3}{|c|}{ no integer solution found } \\
\hline $\mathrm{P} 26 *$ & 4 & 4 & 5 & 694913.30 & $73.78 \%$ & $0.00 \%$ \\
\hline P27 & 4 & 4 & 7 & \multicolumn{3}{|c|}{ no integer solution found } \\
\hline
\end{tabular}

Solution value of the goal programming model, negative percent deviation from profit level, and positive percent deviation from emission level are given in Table 6. Aspiration levels for goal constraints were assumed to be the solution values of single-objective models which are given in Table 4 and Table 5. The problems with the $*$ sign indicates that their optimal solution times were not found in the 64800 seconds solution time. The solution values given for these problems were the best possible integer solutions in 64800 seconds. Only for two instances optimal solutions were obtained. On the other hand, for four instances no integer solution was found.

Obtained results support that finding a trade-off point between conflicting objectives is generally impossible. Only in one test problem, a trade-off point between making more profit and less environmental damage was found.

Also, it is seen that percent deviation from carbon emission objective is less than the percent deviation from profit objective. In most of the problems, solutions less than $10 \%$ deviation from emission aspiration level was found. In addition, the deviation from profit objective was seen to reach $235 \%$. 


\section{CONCLUSIONS}

Supply chain is an approach that aims to make every organization in the chain work for the same objectives, so it is extremely important for companies to effectively manage their processes. Companies should integrate their production and distribution processes in order to be successful in market competition. At this point, supply chain management becomes the main solution for increasing profit and decreasing costs.

Carbon emission that is caused by transportation activities in the production - distribution networks has a great effect on global warming. As a result of this situation, attention on environmental approaches has increased in recent years. According to the regulations on this subject, companies are required to design their supply chains by considering the damage of their production and distribution activities.

In this study, a goal programming model was proposed in order to support production-distribution decisions by taking profit and carbon emission into account simultaneously. In the proposed model, a production system with three level bill-of-materials and a distribution system with different transportation alternatives were integrated and lead times were taken into account, as well. By testing the model with test problems at different dimensions, it is shown that the proposed model can be used as an effective tool for profit and carbon emission optimization in environmentally friendly production-distribution planning.

The main limitations of this study are not being able to predict certain cost and emission values and considering carbon emissions at only two stages. Another limitation of the study is that CPLEX solver could not achieve optimum solutions in some of the problems.

More research into the challenge of obtaining solutions for greater problem dimensions is still necessary. Further research may be conducted by taking carbon emissions and lead times into account for all stages of network. In addition, the proposed model can be extended to real world systems to show the applicability of the model on different systems by adding some specific constraints related to the mentioned system. Also, the model can be converted into a multi-objective model and iterative solution approaches can be applied to it. Supply and demand uncertainties encountered in real world systems can be included into the model by using fuzzy logic or stochastic modelling. Another extension of the proposed model can be the development of heuristic and meta-heuristic solution approaches of the model to see the applicability of the model on problems at greater dimensions.

\section{CONFLICTS OF INTEREST}

No conflict of interest was declared by the authors.

\section{REFERENCES}

[1] Singh, A., "Supplier evaluation and demand allocation among suppliers in a supply chain". Journal of Purchasing \& Supply Management, 20: 167-176, (2013).

[2] Sadrnia, A., Ismail, N., Zulkifli, N., Ariffin, M.K.A., Nezamabadi-pour, H., Mirabi, H., "A Multiobjective Optimization Model in Automotive Supply Chain Networks". Mathematical Problems in Engineering, 1-10, (2013).

[3] Plambeck, E.L., "Reducing greenhouse gas emissions through operations and supply chain management”. Energy Economics, 34: S64-S74, (2012).

[4] IPCC, "Climate Change 2007: Mitigation. Contribution of Working Group III to the Fourth Assessment Report of the Intergovernmental Panel on Climate Change”. in: B. Metz, O.R. Davidson, P.R. Bosch, R. Dave, L.A. Meyer (Eds.), Cambridge, United Kingdom and New York, NY, USA, (2007). 
[5] Torabi, S.A., Hassini, E., "Multi-site production planning integrating procurement and distribution plans in multi-echelon supply chains: an interactive fuzzy goal programming approach". International Journal of Production Research, 47: 5475-5499, (2009).

[6] Franca, R.B., Jones, E.C., Richards, C.N., Carlson, J.P., "Multi-objective stochastic supply chain modeling to evaluate tradeoffs between profit and quality". International Journal of Production Economics, 127: 292-299, (2010).

[7] Bashiri, M., Badri, H., Talebi, J., "A new approach to tactical and strategic planning in productiondistribution networks". Applied Mathematical Modelling, 36: 1703-1717, (2012).

[8] Torabi, S.A., Moghaddam, M., "Multi-site integrated production-distribution planning with transshipment: a fuzzy goal programming approach". International Journal of Production Research, 50: 1726-1748, (2012).

[9] Badri, H., Bashiri, M., Hejazi, T.H., "Integrated strategic and tactical planning in a supply chain network design with a heuristic solution method". Computers \& Operations Research, 40: 1143-1154, (2013).

[10] Paksoy, T., Pehlivan, N.Y., Özceylan, E., “A New Tradeoff Model for Fuzzy Supply Chain Network Design and Optimization". Human and Ecological Risk Assessment: An International Journal, 19: 492-514, (2013).

[11] Peidro, D., Mula, J., Alemany, M.M.E., Lario, F.-C., "Fuzzy multi-objective optimisation for master planning in a ceramic supply chain". International Journal of Production Research, 50: 3011-3020, (2012).

[12] Shaw, K., Shankar, R., Yadav, S.S., Thakur, L.S., "Modeling a low-carbon garment supply chain". Production Planning \& Control, 24: 851-865, (2013).

[13] Ahmadizar, F., Zeynivand, M., "Bi-objective supply chain planning in a fuzzy environment". Journal of Intelligent \& Fuzzy Systems, 26: 153-164, (2014).

[14] Paydar, M. M., Saidi-Mehrabad, M., "Revised multi-choice goal programming for integrated supply chain design and dynamic virtual cell formation with fuzzy parameters". International Journal of Computer Integrated Manufacturing, 28(3): 251-265, (2015).

[15] Altiparmak, F., Gen, M., Lin, L., Paksoy, T., "A genetic algorithm approach for multi-objective optimization of supply chain networks". Computers \& Industrial Engineering, 51: 196-215, (2006).

[16] Pan, F., Nagi, R., "Multi-echelon supply chain network design in agile manufacturing". Omega, 41: 969-983, (2013).

[17] Su, W., Huang, S.X., Fan, Y.S., Mak, K.L., "Integrated partner selection and production-distribution planning for manufacturing chains". Computers \& Industrial Engineering, 84: 32-42, (2015).

[18] Belo-Filho, M.A.F., Amorim, P., Almada-Lobo B., "An adaptive large neighbourhood search for the operational integrated production and distribution problem of perishable products". International Journal of Production Research, 53: 6040-6058, (2015).

[19] Hein, F., Almeder, C., "Quantitative insights into the integrated supply vehicle routing and production planning problem". International Journal of Production Economics, 177: 66-76, (2016).

[20] Moon, I., Jeong, Y. J., Saha, S., "Fuzzy Bi-Objective Production-Distribution Planning Problem under the Carbon Emission Constraint". Sustainability, 8: 798, (2016). 
[21] Taxakis, K., Papadopoulos, C., "A design model and a production-distribution and inventory planning model in multi-product supply chain networks". International Journal of Production Research, 54: 6436-6457, (2016).

[22] Khalifehzadeh, S., Seifbarghy, M., Naderi, B., "Solving a fuzzy multi objective model of a productiondistribution system using meta-heuristic based approaches". Journal of Intelligent Manufacturing, 28: 95-109, (2017).

[23] Miranda, P. L., Morabito, R., Ferreira, D., "Optimization model for a production, inventory, distribution and routing problem in small furniture companies". TOP, 26: 30-67, (2018).

[24] Rafiei, H., Safaei, F., Rabbani M., "Integrated production-distribution planning problem in a competition-based four-echelon supply chain". Computers \& Industrial Engineering, 119: 85-99, (2018).

[25] Charnes A., Cooper W. W., Ferguson R., "Optimal Estimation of Executive Compensation by Linear Programming”. Management Science, 1: 138- 151, (1955).

[26] Dağdeviren, M., Eren, T., "Analytical hierarchy process and use of 0-1 goal programming methods in selecting supplier firm". Journal of the Faculty of Engineering and Architecture of Gazi University, 16: 41-52, (2001).

[27] Karaman, B., Cercioglu, H., "0-1 Goal Programming Aided AHP - VIKOR Integrated Method: An Application of Hospital Investment Project Selection". Journal of the Faculty of Engineering and Architecture of Gazi University, 30: 567-576, (2015).

[28] Aksakal, E., Dagdeviren, M., "Talent Management Based Personnel Assignment Model and Solution Proposal". Journal of the Faculty of Engineering and Architecture of Gazi University, 30: 249-262, (2015).

[29] Garcia-Martinez, G., Guijarro, F., Poyatos, J. A., "Measuring the social responsibility of European companies: a goal programming approach". International Transactions in Operational Research, 26: 1074-1095, (2019).

[30] Sen, N., Nandi, M., "Goal Programming, its Application in Management Sectors- Special Attention into Plantation Management: A Review". International Journal of Scientific and Research Publications, 2: 192-197, (2012). 